\title{
"It has worked well despite the circumstances" - a study on student social relations and well-being during the pandemic
}

\author{
Annika Fjelkner, ${ }^{1 *}$ Torgny Roxå2 \& Per Warfvinge ${ }^{2}$ \\ ${ }^{1}$ Kristianstad University, Sweden; ${ }^{2}$ Lund University, Sweden
}

\begin{abstract}
Students' possibilities to interact with peers have reduced drastically during the emergency transition to online teaching due to the Covid-I9 pandemic. Students report on decreased motivation and other study related issues; hence, there is a need to better understand the effects of decreased interaction. The aim of the present exploratory study was to document changes in student networks, in relation to perceptions of connectedness, study outcome and well-being in two different settings. An ad hoc online survey $(n=97)$ was distributed among students from one research-intensive and one teaching-intensive university where many students commute. Results showed that student social networks defoliated from the outside-in and left students with an inner circle of students they shared multiplex relations with. Students who had lost more working and multiplex relations also reported a decline in well-being. The main contribution of this study is the visualization of how networks became fragmented, and how the experience of this differed depending on type of study context. These findings may have implications for a post-Covid organisation of higher education.
\end{abstract}

Keywords: word, social relations, well-being, commuter students, academic outcome, higher education, multiplex relations, epistemological development

\section{INTRODUCTION}

In this article we focus on how the pandemic has affected students' opportunities to interact with other students and combine graphical representations of students' networks on cohort level with individual students' descriptions of how they perceived the situation during and before the pandemic. The aim is to provide another piece in the puzzle for academic teachers, academic leaders, and others on what we can learn from the pandemic experience.

Students' possibilities to interact with peers have reduced drastically during the emergency transition to online teaching due to the pandemic. According to one study, face to face interaction with peers has decreased with $88 \%$ (Gothenburg University, 2020). Subsequent negative effects on students' well-being have been reported (Elmer et al., 202O; Husky et al., 202O; Savage et al., 2020; Wang et al., 2020/202I). Furthermore, students report on decreased motivation, and problems related to structuring information about courses and dealing with feedback (Warfvinge et al., 202I). It is against the backdrop of such findings, that this study investigates effects on students' study related networks.

Students' study related networks are important for their learning (e.g., Eggens et al., 2007; Fjelkner-Pihl, 202I; McCabe, 20I6). It has been emphasized that students tend to rely on

*Correspondence: Annika Fjelkner, e-mail: annika.fjelkner@hkr.se

Artiklar och reflektioner är kollegialt granskade. Övriga bidragstyper granskas av redaktionen. Se https://hogreutbildning.se ISSN 2000-7558

(C)2021 Annika Fjelkner, Torgny Roxå \& Per Warfvinge. This is an Open Access article distributed under the terms of the Creative Commons Attribution 4.0 International License (https://creativecommons.org/licenses/BY/4.0/), allowing third parties to share their work (copy, distribute, transmit) and to adapt it, under the condition that the authors are given credit, that the work is not used for commercial purposes, and that in the event of reuse or distribution, the terms of this license are made clear.

Citation: Fjelkner, A., Roxå, T. \& Warfvinge, P. (2021). "It has worked well despite the circumstances" - a study on student social relations and well-being during the pandemic", Högre utbildning, 11(3), 9-25. https://doi.org/10.23865/hu.v11.3183 


\section{Annika Fjelkner et al.}

"a myriad of emerging interactions and relations that will shape how students may or may not learn" (Esterhazy, 20I9, p. 73), fulfilling a formative function for students (Hattie, 2008; William, 20II). The "social environment is understood to have an important role in shaping experiences of learners and simultaneously providing a mechanism to test and evaluate new ideas, which may then result in modified or new conceptions of the world" (Henderson et al., 20I9, p. 2I). In sum, university students generally perform better in relationship-rich environments (Felten \& Lambert, 2020), where they meet and interact with a multitude of other students. Therefore, it is possible to hypothesize together with Jeffrey and Bauer (2020), that what some students experience as problematic with online courses during the time of Covid-I9, is that previously dense interactions, foremost with peers, become less dense and thereby less informative. However, the students' experiences may vary depending on study context. For example, students in a university where a majority of students commute may have experienced the transition in a different way than students who study in an environment where many students live close to the university.

Thus, the present explorative study contributes with an exploration of how the Covid-I9 pandemic has affected student study related networks in two different types of universities, in relation to the students' perception of connectedness and study outcome. The aim is to add to a growing knowledge of effects of the pandemic on higher education, in this case on decreased interaction among students and self-reported effects on study outcome. The text also offers a discussion on possible implications for the planning and organization of courses during online conditions like the pandemic experience.

\section{Student social relations and online teaching}

To better understand what it means to be an online student during the pandemic, it can be useful to turn to pre-pandemic research into online teaching. For example, in an elaborated study in an online environment, Theobald et al. (2018) explored the link between study outcome and disciplined study strategies. Results indicate that study discipline more than teaching format (e.g., online) explains the variation in study results. In addition, attempts have been made to positively support student interaction also in online courses, that is to increase the experience of social presence (Oh et al., 20I8). Weidlich \& Bastiaens (2019) added applications supporting interaction to the learning platformed used to increase a sense of connection and community and thereby enhancing the study outcome. However, the result "suggests that socio-emotional perceptions regarding the learning environment and of peers do not actually impact learning" (Weidlich \& Bastiaens, 2019, p. I2). Consequently, even though some research suggests that social presence and dense interaction with others are important for study results, other research suggests a more complicated relationship between social interaction during courses and study outcome.

Thus, even though study discipline comes across as crucial, it is unclear how interaction with others influence study outcome. It might be that different students rely on networks in different ways, something that may explain the variation in the literature (for example Elmer et al., 2020; Warfvinge et al., 202I). In this study we will include a sample of commuter students to see whether they are affected by the pandemic in the same way as campus students. Previous studies have found that commuting often has a negative impact on engagement and that students who commute often take less part in social life at the university (London Higher, 20I9; Yorke \& Longden, 2008), but whether the pandemic has negatively affected their experience has not yet been researched. 
Student social relations in and around the classroom

Network studies in higher education have explored various types of relations, commonly student working, learning or friendship relations (e.g., Hommes et al., 20I4; Rienties \& Tempelaar, 20I8). Students' study-related networks provide emotional and social support, but also information and cognitive processing support (Thomás-Miquel et al., 20I6). Relations studied are often described as either intrumental or expressive. Student working relations (instrumental) explore with whom students communicate about task-related activities (Rienties \& Tempelaar, 20I8), such as how to solve an assignment, whereas friendship relations (expressive) are not bound to any formal structure (e.g., work relations), such as an assigned group, but on voluntary interaction (Methot et al., 2016).

Social relations among students are often based on homophily (e.g., Fjelkner-Pihl, 202I), the tendency to prefer forming relations with others you perceive as similar regarding socioeconomic background, age, cultural preferences, or ethnicity. This could potentially lead to less interaction with others who think differently, that is, being less disturbed in their own thinking, something that potentially could undermine long-term epistemological development (O’Donovan, 20I7; Perry, 1988).

Students often share several types of relations, and these multiplex relations are rewarding for students as they are both expressive and instrumental at the same time as they contribute with both emotional and instrumental support, as well as intellectual engagement and inspiration (Fjelkner-Pihl, 202I; McCabe, 20I6). Elmer et al. (2020) have shown that if students shared two types of relations (interaction, friendship, informational, or emotional support) the relations were more likely to be maintained during the pandemic. However, the relations explored were part of an open network (e.g., Tómas-Miquel et al., 2016), that is students could name any ten relations of their choice. In contrast, the present study specifically explores student study related relations within a given cohort, a so-called closed network, that is the relations that are formed and maintained in and around the classroom and thereby arguably closer to study-tasks. The result of such a study may contribute with insights important for teachers, the organization, and the execution of future post-pandemic higher education.

A further issue addressed here concerned whether students in a research-intensive university report a different experience during the pandemic than do students in a teaching-intensive university, where a large share of students commute. Thus, it is probable that there are differences in experiences between these groups.

Questions in focus are:

(I) What are the effects of the Covid-I9 pandemic on students' study related networks in two types of universities?

(2) How do students describe the effects of the Covid-I9 pandemic on their social network in relations to study outcome and cooperation with other students?

\section{METHOD}

Study site

The present study was carried out in two cohorts of students from a research-intensive technical university, Lund University's Faculty of Engineering (LTH), and one cohort of business students from a teaching-intensive university, Kristianstad University (HKR). Lund university is one of the oldest and largest research universities in the country, with over 40,000 students. 


\section{Annika Fjelkner et al.}

Kristianstad university is a younger, regional university focusing mainly on undergraduate education. It has approximately I5,000 students. The composition of enrolled students differs between the universities. Students at HKR more often come from non-academic backgrounds, they have relatively lower grade point average (GPA) from upper secondary school and lower mean SweSAT scores. They are also more likely to commute longer distances.

\section{Sample, procedure and ethical considerations}

Students were in the middle of their third year; thus, they had presumably formed both friendship and working relations within their respective programs. Relational data was collected via an online survey distributed via e-mail in late fall 2020. 97 out of 319 students responded to the survey leading to a $30 \%$ response rate. The completion time was about Io minutes.

Students were approached during an online lecture and were informed about the purpose of the survey, the procedure and that participation was voluntary. Students were further ensured confidentiality in the handling and presentation of data, in line with ethical guidelines of the university (Lund University, 202I). Even though two of the authors were affiliated to two of the programs, none of them were actively engaged in teaching at the time of the survey.

\section{Networks}

The first part of the survey explored working, and friendship relations maintained prior to Covid-19, while students still studied on campus, and after the transition to online teaching. A closed network, roster recollection method (e.g., Rienties \& Templaar, 20I8; Tómas-Miquel et al., 20I6) was used, that is, students were asked to select the students they were friends with from a list of names of all the students registered in their present program course.

Students were first presented with two conditions. They were asked to reflect on their study situation in early spring 2020, before teaching was shifted to online due to Covid-I9, and then mark whom "you frequently cooperate with when you study," and whom "you socialize/are friends with." After that they were asked to reflect upon their study situation right now (during online teaching) and then mark students they socialize with or frequently cooperate with.

Students were also asked to reflect upon two open questions regarding if and how their study related network had changed due to the transition from campus to online teaching, and if and how that transition had affected their study outcome.

\section{Demographic predictors}

Demographic predictors in the present study included gender and whether student commuted. Students reported on place of residence both prior to and after the transition ( $\mathrm{Q}_{2}$ and $\left.\mathrm{Q}_{4}\right)$. Previous research has shown that these factors affect academic outcome (e.g., Krause et al., 2005; Thomas, 2019). Responses were then collapsed into a dummy variable ( $\mathrm{I}=$ non-commuter; $2=$ commuter). Students who lived in the city where their university was located were considered non-commuters.

\section{Analysis}

Freeman's out-degree centrality was used to measure centrality for the working and friendship networks (Grunspan et al., 20I4). The out-degree measures the number of outgoing ties indicating how influential actors are in the network and how many others they can exchange information with (Hanneman \& Riddle, 2005). The analysis of friendship and working networks in program A at LTH was carried out in UCINET and networks were visualized in NetDraw (Borgatti et al., 2002). The higher response rate in that cohort was maybe due to that one of the 
authors had taught parts of a course in that cohort earlier in the fall semester 2020. That author did not handle the collection or analysis of the data. It could also be due to the high number of female students in the group, or the fact that they felt the focus of the survey was important to them.

The answers collected through the open questions were analyzed and coded. First all three authors coded student answers regarding study outcome, cooperation with other students and well-being as either worse, same, or better. The coding was then compared and modified, before used in the statistical analysis. Vague answers were coded as missing. The open answers were thematically coded by two authors individually, then discussed and refined before arriving at the results presented here.

In the statistical analyses, Dependent-samples t-test were used to test for group level difference in network size under the two conditions pre-Covid campus teaching and during Covid-I9 online teaching. Independent-samples t-tests were used to test for group level differences in networks and self-reported well-being, cooperation, and study outcome between student groups. Student descriptions of their well-being and cooperation with other students were coded as qualitative variables: Worse $=1$, Same/better $=2$. A Chi-square tests for independence was used to explore the relationship between these qualitative variables. Finally, a One-way between-groups analysis of variance (ANOVA) was conducted to explore the impact of difference in number of relations on self-reported study outcome. Qualitative responses regarding study outcome were coded as a qualitative variable with three categories (worse/same/better).

Differences were considered statistically significant if $p<0.05$, two-tailed. SPSS (IBM Corp. Released 2016. IBM SPSS Statistics for Windows, Version 24.o. IBM Corp.) was used for all analyses.

\section{RESULT}

The result section is divided in four parts: I) presentation of the sample, 2) group level analysis of how the emergency transition has affected students' study related networks, 3) statistical analysis of the network data, and finally 4) the themes emerging from students' answerers to the open questions.

\section{The sample}

The total sample $(n=97)$ consists of responses from three different study programs as displayed in Table $1.59 \%$ of the participants were females and 33\% commuted to school. One major difference between the two schools that was thought to impact students' school related networks and the experience of the transition to online teaching was the share of students who commuted to school. $68 \%$ of the participants from HKR commuted as compared to 9 and $4 \%$ respectively in the two programs from LTH. We can also note that LTH in this study is considered a research-intensive university, while HKR is considered a teaching-intensive university.

Table I. Sample characteristics

\begin{tabular}{lcccccc}
\hline & \multicolumn{3}{c}{ LTH } & & HKR & \\
\cline { 2 - 3 } & Program A & Program B & & Program C & All \\
\hline Number of respondents & 33 & 22 & & 42 & 97 \\
Female students (\%) & $6 \mathrm{I}$ & 55 & & 59 & 59 \\
Commuters (\%) & 9 & 4 & & 68 & 33 \\
\hline
\end{tabular}




\section{Annika Fjelkner et al.}

How study related networks were impacted by the pandemic: working, friendship, and multiplex relations

Due to sufficient response rate in program A (70\%) the entire network was analyzed (Rienties \& Tempelaar, 20I8) in Ucinet (Borgatti et al., 2002) to illustrate the changes in study related networks due to the transition. The network data is presented in Table 2 and the networks are visualized in Figure I.

Overall in program A, students lost more than $50 \%$ of their study related relations, and as much as $57 \%$ of their multiplex relations, that is students they both cooperated and socialized with. In figure I the networks to the left depict student friendship, working and multiplex networks pre-Covid, when teaching took place on campus. The networks to the right depict the same relations after the transition to online teaching.

Table 2. Descriptive statistics of friendship and study networks in program A, prior to and during the pandemic

\begin{tabular}{|c|c|c|c|c|c|}
\hline \multirow[b]{2}{*}{ Network } & \multicolumn{2}{|c|}{$\begin{array}{c}\text { Pre-Covid-rg } \\
\text { Campus teaching }\end{array}$} & \multicolumn{2}{|c|}{$\begin{array}{l}\text { During pandemic } \\
\text { Online teaching }\end{array}$} & \multirow[b]{2}{*}{ Loss (\%) } \\
\hline & $\sum$ ties & $M(S D)$ & $\sum$ ties & $M(S D)$ & \\
\hline Friendship & 472 & I4.3 (9.99) & 227 & 6.9 (6.9I) & 52 \\
\hline Working & 215 & $6.5(5.39)$ & I03 & 3.I (I.76) & 52 \\
\hline Multiplex & 186 & $4.0(0.28)$ & 79 & I.7 (0.19) & 57 \\
\hline
\end{tabular}

In line with previous research, students generally have more friendship relations overall than work relations (e.g., Fjelkner-Pihl, 202I; Rienties \& Tempelaar, 2018). Pre-Covid, the friendship network ( $A$ in Figure $\mathrm{I}$ ) consisted of a total of 472 friendship ties, and had one very dense cluster to the right in the figure consisting of about a third of the students. Two thirds of the students are more peripheral, but still had ties with the dense cluster. Only one isolate is visible. After the transition to online teaching, the network became more fragmented. There are now five isolates and four clusters, where one is more dense. The working network (B in Figure I) had a total of 215 ties or $55 \%$ less ties than the friendship network. Also here, the transition to online teaching resulted in an even more fragmented network. Interestingly, there are no isolates, or students with no relations, in the working network, meaning that students still cooperated with a few other students, but did not always socialize with these.

The multiplex network largely mirror the working network, but is even more fragmented after the transition. Students only socialized and worked with those they share strong ties with, more peripheral ties were not maintained. Generally, this picture was strengthened by student responses to the open ended questions in the survey.

Changes in student social relations due to Covid-19 and the transition to online teaching The above case visualized the loss of relations in one specific cohort of students. The further analysis of all responses in the study confirms the detailed study of program A that students experienced a loss of relations in all three network types, and that the number of relations maintained differed between the two universities (Table 3).

A paired sample t-test, testing the pre-Covid and Online condition for the different networks indicated significant differences in both universities, although the loss in actual numbers was larger at LTH, where students overall had more relations than did students at HKR in this sample. 


\section{Campus teaching}

A) Friendship network

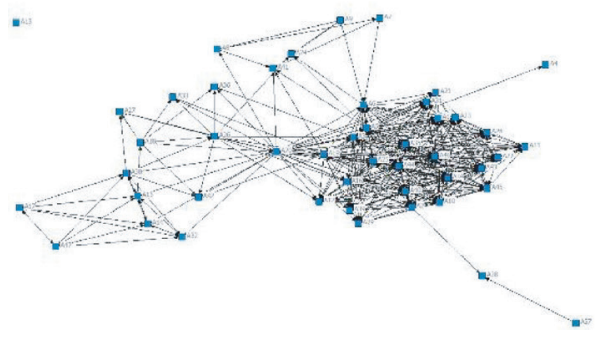

B) Working network

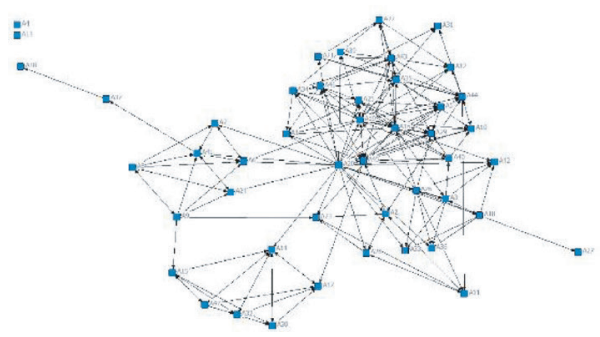

C) Multiplex network

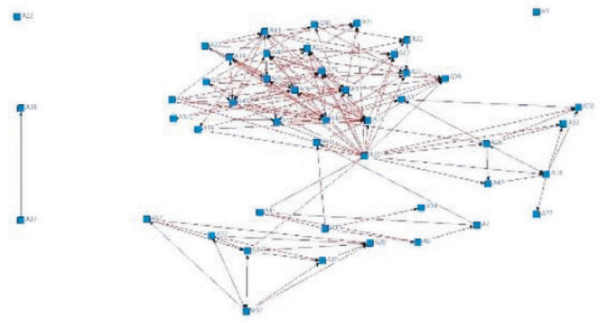

\section{Online teaching}
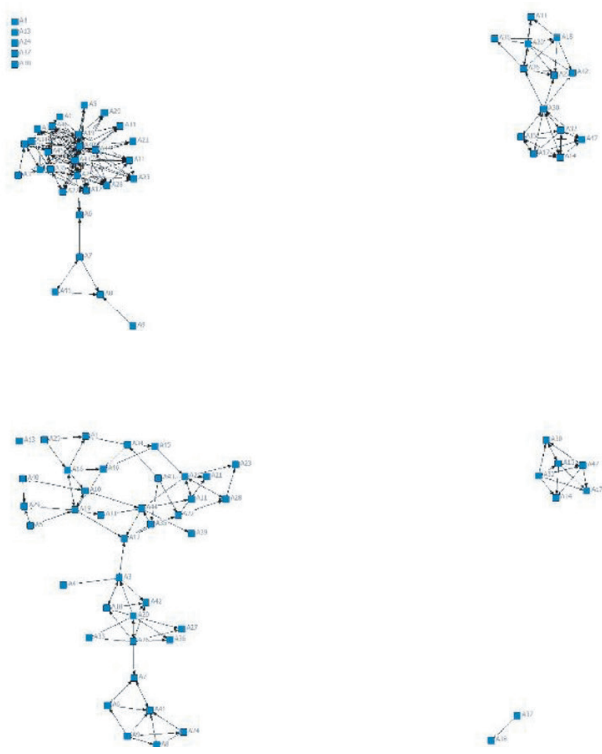

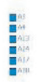

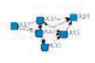

is

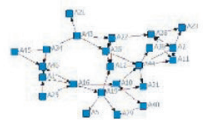

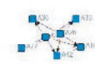

Figure I. Student social networks in group A: pre-Covid-Ig campus teaching vs. online teaching Note: The networks to the left depict student relations prior to Covid-Ig and the networks to the right relations that remained after the transfer to online teaching. A relation is considered multiplex when a student both cooperate and socialize with another node (red ties in $C$ above).

Table 3. Changes in study related networks at HKR and LTH prior to the pandemic and after the transition to online teaching

\begin{tabular}{|c|c|c|c|c|c|c|c|c|}
\hline & & \multicolumn{2}{|c|}{ Pre-Covid } & \multicolumn{2}{|c|}{ Online } & \multicolumn{3}{|c|}{ Paired sample t-test } \\
\hline & & $M$ & $S D$ & $M$ & $S D$ & $t$ & $d f$ & $p$ \\
\hline \multirow[t]{3}{*}{ LTH } & Friends NW & I6.I7 & 15.26 & 8.60 & 9.87 & 6.28 & 54 & $<.001$ \\
\hline & Work NW & 7.09 & 5.49 & 4.04 & $3.3 \mathrm{I}$ & 5.63 & 54 & $<.001$ \\
\hline & MPX NW & 5.98 & 5.II & 3.25 & $3 . \mathrm{II}$ & 5.62 & 54 & $<.001$ \\
\hline \multirow[t]{3}{*}{ HKR } & Friends NW & $3.2 \mathrm{I}$ & 3.12 & 2.29 & 2.83 & 3.40 & $4 \mathrm{I}$ & $<.002$ \\
\hline & Work NW & 4.90 & $3.5 \mathrm{I}$ & $3.8 \mathrm{I}$ & 2.98 & $3.5 \mathrm{I}$ & $4 \mathrm{I}$ & $<.001$ \\
\hline & MPX NW & 2.74 & 2.66 & І. 86 & 2.30 & 3.II & $4 \mathrm{I}$ & $<.003$ \\
\hline
\end{tabular}




\section{Annika Fjelkner et al.}

Further analyses indicated significant differences in the number of relations students maintained between LTH and HKR, and between non-commuter and commuter students, both prior to the outbreak of Covid-I9 and after the transition to online teaching (Table 4).

Table 4. T-result comparing networks under the two conditions pre-Covid-I9 campus teaching vs. online teaching

\begin{tabular}{|c|c|c|c|c|c|c|}
\hline Variable & School & $M(S D)$ & Median & Range & $t(d f)$ & $p$ \\
\hline \multirow{2}{*}{$\begin{array}{l}\text { Working NW } \\
\text { Pre-Covid }\end{array}$} & LTH & $7.09(5.49)$ & 6 & $0-27$ & $2.38(92.4)$ & $<.019$ \\
\hline & HKR & $4.90(3.5 \mathrm{I})$ & 4 & $\mathrm{O}-13$ & & \\
\hline \multirow{2}{*}{$\begin{array}{l}\text { Friendship NW } \\
\text { Pre-Covid }\end{array}$} & LTH & I6.I6 (I5.26) & I8 & $0-7 I$ & $6.13(59.8)$ & $<.001$ \\
\hline & HKR & $3.2 \mathrm{I}(3 . \mathrm{II})$ & 2 & O-II & & \\
\hline \multirow{2}{*}{$\begin{array}{l}\text { MPX NW } \\
\text { Pre-Covid }\end{array}$} & LTH & $5.98(3.25)$ & 5 & $0-24$ & $4.05(85.0)$ & $<.001$ \\
\hline & HKR & $2.74(\mathrm{I} .86)$ & I. 5 & O-II & & \\
\hline \multirow{2}{*}{$\begin{array}{l}\text { Working NW } \\
\text { Online }\end{array}$} & LTH & $4.04(3.32)$ & 3 & O-IS & $0.35(95)$ & ns \\
\hline & $\mathrm{HKR}$ & $3.8 \mathrm{I}(2.98)$ & 3 & $\mathrm{O}-\mathrm{I} 3$ & & \\
\hline \multirow{2}{*}{$\begin{array}{l}\text { Friendship NW } \\
\text { Online }\end{array}$} & LTH & $8.60(9.86)$ & 5 & $\mathrm{O}-48$ & $4.5 \mathrm{I}(65.4)$ & $<.001$ \\
\hline & $\mathrm{HKR}$ & $2.29(2.85)$ & I & O-II & & \\
\hline \multirow{2}{*}{$\begin{array}{l}\text { MPX NW } \\
\text { Online }\end{array}$} & LTH & $3.25(3 . \mathrm{II})$ & 3 & O-II & $2.54(94.9)$ & $<.016$ \\
\hline & $\mathrm{HKR}$ & I. $86(2.30)$ & I & $\mathrm{O}-\mathrm{II}$ & & \\
\hline \multirow{2}{*}{$\begin{array}{l}\text { Working NW } \\
\text { Pre-Covid }\end{array}$} & Non-commuters & $7.22(5.08)$ & 6 & $0-27$ & $3.78(89.1)$ & $<.001$ \\
\hline & Commuters & $3.97(3.24)$ & 3 & $\mathrm{O}-\mathrm{I} 2$ & & \\
\hline \multirow{2}{*}{$\begin{array}{l}\text { Friendship NW } \\
\text { Pre-Covid }\end{array}$} & Non-commuters & I4.24 (I4.68) & 8 & O-7I & $5.73(80.7)$ & $<.001$ \\
\hline & Commuters & $3.06(3.97)$ & 2 & $0-20$ & & \\
\hline \multirow{2}{*}{$\begin{array}{l}\text { MPX NW } \\
\text { Pre-Covid }\end{array}$} & Non-commuters & $5.78(4.82)$ & 5 & $0-24$ & 5.0I (94.9) & $<.001$ \\
\hline & Commuters & $2.12(2.37)$ & I.5 & $\mathrm{O}-9$ & & \\
\hline \multirow{2}{*}{$\begin{array}{l}\text { Working NW } \\
\text { Online }\end{array}$} & Non-commuters & $4.40(3.47)$ & 4 & $\mathrm{O}-\mathrm{I} 5$ & $2.43(89.5)$ & $<.017$ \\
\hline & Commuters & $3.00(2.17)$ & 2 & $0-7$ & & \\
\hline \multirow{2}{*}{$\begin{array}{l}\text { Friendship NW } \\
\text { Online }\end{array}$} & Non-commuters & 7.9I (9.33) & 5 & $\mathrm{O}-48$ & $5.08(76.8)$ & $<.001$ \\
\hline & Commuters & I.72(2.I6) & I & $0-7$ & & \\
\hline \multirow{2}{*}{$\begin{array}{l}\text { MPX NW } \\
\text { Online }\end{array}$} & Non-commuters & $3.32(3.13)$ & 3 & O-II & $4.37(94.8)$ & $<.001$ \\
\hline & Commuters & $\mathrm{I} .28(\mathrm{I} .46)$ & I & $0-5$ & & \\
\hline
\end{tabular}

Overall, students at LTH had a higher mean number of both friendship and working relations, both prior to Covid-I9 and after the transition to online education. However, the variation was quite high, especially at LTH, where there was a wide range in number of friendship ties (o-7I) and higher standard deviations than at HKR.

T-test results indicated significant differences between the mean number of friendship relations between LTH and HKR ( $\mathrm{p}$ <.ooI) both before and after the transition to online education $(p<$. .ooI). This was also the case with the working relations on campus $(\mathrm{p}<$. .oIg), but after the transition to online teaching that difference had even out and there was no longer any significant difference between the two schools. 
Regarding difference in relations between commuter and non-commuter students, there were significant differences between the mean number of friendship relations on campus between non-commuter and commuter students $(p<$. .OoI), and after the transition to online education $(p<$. .ooI $)$. This was also the case regarding working relations on campus $(p<.004)$ and after the transition to online education, although the difference had evened out slightly $(p<.023)$. Overall, non-commuter students had both more friendship and working relations than did students who commuted. As could be expected, the difference between commuters and non-commuters working network was evened out after the transition to online teaching, and as restrictions limited personal interaction.

\section{Association between background variables and reports of well-being and cooperation}

Chi-square tests were used to explore if there is an association between variables such as gender, school and commuting with reported well-being and cooperation with other students. 95 out of 97 students responded to the open-ended questions. A larger share of students at LTH (44\%) compared to $29 \%$ at HKR felt worse (Table 5 ).

Regarding cooperation with other students, there was a tendency for association for gender and cooperation, as a larger share of male students (73\%) found that the cooperation with other students was worse when teaching took place online than when it took place on campus as compared to $55 \%$ of the female students. The result was marginally significant with a p-value of .072 , confirming a trend seen in a previous study of Course Experience Questionnaire results at LTH from spring term in 2020 (Warfvinge et al., 202I).

Table 5. Crosstabulation of gender, school, and commuting, with well-being/cooperation with other students

\begin{tabular}{|c|c|c|c|c|c|c|c|c|c|}
\hline & $\begin{array}{l}\text { Males } \\
\text { n (\%) }\end{array}$ & $\begin{array}{c}\text { Females } \\
\text { n (\%) }\end{array}$ & $X^{2}$ & $\begin{array}{r}\text { LTH } \\
\text { n (\%) }\end{array}$ & $\begin{array}{l}\text { HKR } \\
\text { n (\%) }\end{array}$ & $X^{2}$ & $\begin{array}{c}\text { Non- } \\
\text { commuter } \\
\text { n (\%) }\end{array}$ & $\begin{array}{c}\text { Commuter } \\
\text { n (\%) }\end{array}$ & $X^{2}$ \\
\hline \multicolumn{10}{|l|}{ Well-being } \\
\hline Worse & I2 (33) & I8 (38) & \multirow{2}{*}{.218} & I8 (44) & I2 (29) & \multirow{2}{*}{ 2.II } & 2I (40) & $9(29)$ & \multirow{2}{*}{ I.084 } \\
\hline Same/better & $24(77)$ & $29(62)$ & & $23(56)$ & $30(7 \mathrm{I})$ & & 3I $(60)$ & $22(7 \mathrm{I})$ & \\
\hline \multicolumn{10}{|l|}{ Cooperation } \\
\hline Worse & $29(73)$ & $30(55)$ & \multirow{2}{*}{$3.17^{*}$} & $35(66)$ & $24(57)$ & \multirow{2}{*}{0.79} & 4I (65) & I8 (56) & \multirow[b]{2}{*}{.703} \\
\hline Same/better & II (27) & $25(45)$ & & I8 (34) & I8 (43) & & $22(35)$ & I4 (44) & \\
\hline
\end{tabular}

Note: * $p$-value: .072; student descriptions of their well-being and cooperation with other students were coded as qualitative variables as: Worse $=\mathrm{I}$, Same/better $=2$.

Association between background variables and the change in number of friendship and working relations after the transition from campus to online teaching

Independent sample t-tests indicated that there were significant differences in scores between the two schools regarding changes in the working network, and in the friendship networks. This was also the case regarding the scores for non-commuters and commuters, which is to be expected since there was a substantial overlap between school and commuting. $68 \%$ of students from the HKR were commuters, whereas only $7 \%$ from LTH. The pattern was the same for the multiplex network. Overall, students from LTH, and non-commuters, experienced the greatest changes in their networks due to Covid-I9 and the change from campus to online teaching (Table 6). 
Table 6. Association between background variables and change in networks relations

\begin{tabular}{|c|c|c|c|c|}
\hline & Variable & $M(S D)$ & $t(d f)$ & $p$ \\
\hline \multirow[t]{2}{*}{ Diff Working NW } & LTH & $3.05(4.03)$ & \multirow{2}{*}{$3.13(83.6)$} & \multirow[b]{2}{*}{$<.002$} \\
\hline & HKR & I.IO $(2.02)$ & & \\
\hline \multirow[t]{2}{*}{ Diff Friendship NW } & LTH & $7.56(8.94)$ & \multirow{2}{*}{$5.37(59.4)$} & \multirow{2}{*}{$<.00 I$} \\
\hline & HKR & 0.92 (I.77) & & \\
\hline \multirow[t]{2}{*}{ Diff MPX NW } & LTH & $2.73(3.60)$ & \multirow{2}{*}{$3.29(84.24)$} & \multirow{2}{*}{$<.00 I$} \\
\hline & HKR & 0.88 (I.84) & & \\
\hline \multirow[t]{2}{*}{ Diff Working NW } & Non-commuters & $2.8 \mathrm{I}(4.03)$ & \multirow{2}{*}{$3.12(94.5)$} & \multirow{2}{*}{$<.002$} \\
\hline & Commuters & 0.97 (2.0I) & & \\
\hline \multirow[t]{2}{*}{ Diff Friendship NW } & Non-commuters & $6.34(8.42)$ & \multirow{2}{*}{$4.05(94.2)$} & \multirow[b]{2}{*}{$<.00 I$} \\
\hline & Commuters & $\mathrm{I} .34(3.70)$ & & \\
\hline \multirow[t]{2}{*}{ Diff MPX NW } & Non-commuters & $2.46(3.50)$ & \multirow{2}{*}{$3.13(94.5)$} & \multirow{2}{*}{$<.002$} \\
\hline & Commuters & $0.84(\mathrm{I} .59)$ & & \\
\hline
\end{tabular}

Association between change in the working and friendship networks and reports of well-being and cooperation

Independent-sample t-test was conducted to explore association between mean change in working and friendship relations and reports of well-being and cooperation (Table 7). Overall, the mean loss of relations for students who indicated they felt worse, or that the cooperation between students was worse when teaching was conducted online, was larger than the mean loss for students who reported that well-being or cooperation was the same or better.

Regarding well-being, there was significant difference in the mean change in the working networks for students who reported a decline in well-being and students who reported no change or improvement in well-being. Likewise, there was a significant difference in the mean change in multiplex network relations, where students who reported a decline in well-being on average lost 3.59 multiplex relations as compared to 0.93 for the group same or better. Overall, the result indicated that students who reported a decline in well-being had lost more work and multiplex relations on average.

Table 7. Association between change in number of networks relations, and well-being and cooperation

\begin{tabular}{|c|c|c|c|c|c|c|}
\hline & & & $M$ & $S D$ & $t(d f)$ & $p$ \\
\hline \multirow[t]{6}{*}{ Well-being } & \multirow[t]{2}{*}{ Diff Working NW } & Worse & 3.33 & 4.57 & \multirow{2}{*}{2.26} & \multirow{2}{*}{$<.05$} \\
\hline & & Same or better & I. 57 & 2.55 & & \\
\hline & \multirow[t]{2}{*}{ Diff Friendship NW } & Worse & 6.43 & 8.30 & \multirow{2}{*}{ I. 668} & \multirow{2}{*}{ ns } \\
\hline & & Same/better & 3.55 & 7.13 & & \\
\hline & \multirow[t]{2}{*}{ Diff MPX NW } & Worse & 3.59 & 4.43 & \multirow{2}{*}{2.577} & \multirow{2}{*}{$<$. OI } \\
\hline & & Same or better & 0.93 & I.94 & & \\
\hline \multirow[t]{6}{*}{ Cooperation } & \multirow[t]{2}{*}{ Diff Working NW } & Worse & 2.44 & 4.03 & \multirow{2}{*}{$0.75 \mathrm{I}$} & \multirow{2}{*}{ ns } \\
\hline & & Same or better & I. 89 & 3.83 & & \\
\hline & \multirow[t]{2}{*}{ Diff Friendship NW } & Worse & 5.12 & 7.72 & \multirow{2}{*}{0.798} & \multirow{2}{*}{ ns } \\
\hline & & Same or better & 3.83 & 7.44 & & \\
\hline & \multirow[t]{2}{*}{ Diff MPX NW } & Worse & I.93 & 2.9I & \multirow{2}{*}{0.023} & \multirow{2}{*}{ ns } \\
\hline & & Same or better & I.92 & 3.48 & & \\
\hline
\end{tabular}


There was no significant difference in the mean change in the friendship networks between the two groups, which seems to indicate a relative importance of the work and multiplex relations for well-being.

Regarding cooperation, there was no significant difference in the result, although students who reported that cooperation was worse than before due to Covid-rg had lost slightly more work and friendship relations than had students who reported that cooperation was the same or better.

Association between change in the working and friendship networks and outcome

A one-way between-groups analysis of variance was conducted to explore the impact of difference in number of relations on self-reported study outcome. Participants were divided into three groups based on their responses to how they thought the transition to online teaching had affected study outcome (worse/same/better). There was no statistically significant difference between groups, although overall students who reported they did less well had also lost more relations on average (Table 8).

However, when the scores of the two groups non-commuters and commuters were compared significant differences were found for commuters and differences in the multiplex and work networks at the $p<.05$ level in the LOT scores for the three groups. Commuter students who reported they did worse regarding study outcome during the pandemic had lost more relations in their multiplex networks.

Table 8. Association between change in number of networks relations and self-reported study outcome

\begin{tabular}{|c|c|c|c|c|c|c|}
\hline & & Study outcome & $M$ & $S D$ & $F(d f)$ & $p$ \\
\hline \multirow[t]{9}{*}{ All } & \multirow[t]{3}{*}{ Diff Working NW } & Worse & 2.67 & 3.18 & \multirow[t]{3}{*}{.46} & \multirow[t]{3}{*}{ ns } \\
\hline & & Same & 2.33 & 4.18 & & \\
\hline & & Better & I. 54 & 1.76 & & \\
\hline & \multirow[t]{3}{*}{ Diff Friendship NW } & Worse & 6.50 & 7.86 & \multirow[t]{3}{*}{ I.I6 } & \multirow[t]{3}{*}{$\mathrm{ns}$} \\
\hline & & Same & $4 \cdot 48$ & 8.15 & & \\
\hline & & Better & 2.85 & $5.7 \mathrm{I}$ & & \\
\hline & \multirow[t]{3}{*}{ Diff MPX NW } & Worse & 2.70 & 2.77 & \multirow[t]{3}{*}{ I. 72} & \multirow[t]{3}{*}{ ns } \\
\hline & & Same & I.96 & $3.7 \mathrm{I}$ & & \\
\hline & & Better & .77 & $\mathrm{I} . \mathrm{I7}$ & & \\
\hline \multirow[t]{9}{*}{ Commuters } & \multirow[t]{3}{*}{ Diff Working NW } & Worse & 2.30 & 2.83 & \multirow[t]{3}{*}{$4.36(2,26)$} & \multirow[t]{3}{*}{$<.023$} \\
\hline & & Same & $.2 \mathrm{I}$ & .97 & & \\
\hline & & Better & .20 & .45 & & \\
\hline & \multirow[t]{3}{*}{ Diff Friendship NW } & Worse & I.3O & 2.06 & \multirow[t]{3}{*}{ I.66 } & \multirow[t]{3}{*}{ ns } \\
\hline & & Same & .43 & .85 & & \\
\hline & & Better & 4.00 & 8.94 & & \\
\hline & \multirow[t]{3}{*}{ Diff MPX NW } & Worse & I.90 & 2.02 & \multirow[t]{3}{*}{$5.50(2,26)$} & \multirow[t]{3}{*}{$<0.01$} \\
\hline & & Same & .36 & .842 & & \\
\hline & & Better & -.20 & .45 & & \\
\hline
\end{tabular}


Table 8. (Continued)

\begin{tabular}{|c|c|c|c|c|c|c|}
\hline & & Study outcome & $M$ & $S D$ & $F(d f)$ & $p$ \\
\hline \multirow{9}{*}{$\begin{array}{l}\text { Non- } \\
\text { commuters }\end{array}$} & \multirow[t]{3}{*}{ Diff Working NW } & Worse & 2.85 & 3.34 & \multirow[t]{3}{*}{.18} & \multirow[t]{3}{*}{$\mathrm{ns}$} \\
\hline & & Same & 3.25 & 4.62 & & \\
\hline & & Better & 2.38 & I. .77 & & \\
\hline & \multirow[t]{3}{*}{ Diff Friendship NW } & Worse & 9.10 & 8.42 & \multirow[t]{3}{*}{2.03} & \multirow[t]{3}{*}{$\mathrm{ns}$} \\
\hline & & Same & 6.25 & 9.24 & & \\
\hline & & Better & 2.13 & 2.95 & & \\
\hline & \multirow[t]{3}{*}{ Diff MPX NW } & Worse & 3.IO & 3.04 & \multirow[t]{3}{*}{.65} & \multirow[t]{3}{*}{ ns } \\
\hline & & Same & 2.66 & 4.25 & & \\
\hline & & Better & I. 38 & I.06 & & \\
\hline
\end{tabular}

Students who reported they had the same outcome as before the pandemic had only lost on average 0.4 relations. Post-hoc comparisons using the Bonferroni test indicated that mean scores for students who did worse was significantly different from students who did the same or better.

\section{Student responses to open-ended questions}

This part reports on findings from the thematic analysis of responses to the open-ended questions in the survey, which were included with the aim to shed further light on certain aspects of the quantitative findings, such as the loss of peripheral relations and supportive formative feedback and problem solving that took place in and around the classroom.

$30 \%$ reported that the transition had had a negative impact on their study outcome. At the same time a majority of students indicated that $48 \%$ of the students in this sample did not find that the transition to online teaching had had a substantial effect on their study outcome, and for some ( $15 \%)$ the transition had even led to better study result. Reasons pointed out were the ability to plan their time better and more time to study due to less social interaction and less time spent commuting (Table 9). Regarding their study outcome, students reflected on how they could now study at their own pace, they did not have to spend time socializing, and maybe also the format of the examination or the grading had changed making it easier to pass. They also pointed out that they had kept a small but supportive network which had aided them in their studies.

Table 9. Student responses regarding improved study outcome

I do better. I think because I do not have to commute which gives me more time, but also because the group I study with are good at making sure that we spend enough time. If I did not study via Zoom with my group my results would have deteriorated. (A6)

As I have started to study more on my own, I have to say it goes better compared to when I studied with others. Now I focus more on school and less on socializing with others. (C4I)

For some, and especially for the commuter students (C4I) the interaction with their innermost circle continued almost as usual, and they simply met using digital tools such as Zoom or communicated frequently via different social media (Table ro). 
Table Io. Student responses regarding studying using digital tools

But luckily one have used Zoom a lot in the groups and helped each other. Zoom has not only been used for lectures. Group dynamics has been great so that is why there has been no obstacles/difference apart from that we do not meet IRL. $(\mathrm{C} 5)$

Zoom is really a very good and useful tool. [...] Of course, I miss the social bit [...] but me and my friends still have some contact via social media and Zoom from time to time. $\left(\mathrm{C}_{27}\right)$

At the same time responses indicated a sense of loss, or sadness in missing the interaction in and around the classroom as $60 \%$ of the students reported that the interaction between students had deteriorated. They kept their innermost circle of students they worked closely with but did not interact at all with more peripheral peers, indicating that it is foremost the peripheral study related relationships that are were dropped; thus, the personal network was defoliated from outside in, as students now only interacted with a small core group of peers. Many further expressed how they missed getting other perspectives on things as they only or mostly communicated with the same small number of peers (Table II).

\section{Table II. Student responses regarding defoliation of study related networks}

Those I studied the most with I have continued studying with. Those that I studied less with have completely vanished which is sad. However, the relationship with the students I study with have gone from being just superficial study mates to actually develop into real friendship during this time. $\left(\mathrm{A}_{44}\right)$

Before you could bump into people in class in school. Now the circle of friends is more limited, and I never meet new people. I socialize a lot with old friends and seldom get new perspectives on things as you are so isolated. As most social events where you could previously meet acquaintances were cancelled you have had no possibility to come close to any new [people]. (B2I)

Students further pointed to the informal activity that goes on in and around the classroom, that is, the constant sharing of what goes on in a course, what is required of different assignments and what the course literature is really saying. This flow of formative feedback was hard to maintain or recreate in an online environment (Table I2). This experience was more frequent among campus respondents compared to commuter students.

Table I2. Student responses regarding lack of information and formative feedback

The biggest difference is not meeting the teacher physically. [...] which for some reason has led to insecurity and being unsure of assignments, demands and deadlines. Maybe it is so that discussions about these issues are brought up more often in a physical classroom than in a digital one, thanks to the dynamics between students in the physical environment. ( $\left.\mathrm{C}_{42}\right)$

Then you bumped into people on campus and often asked someone who sat close to you. Then you could realize that you were on the same level/had gotten as far and then you continued together. (A26)

I think the online teaching could be developed to reach out to more students. Personally, I learn better in a classroom and [when] I have the possibility to ask questions and another possibility to dialogue with the teacher. $\left(\mathrm{C}_{4}\right)$

\section{DISCUSSION}

In our sample students reported a loss of ties sometimes as high as 50\%, as they moved into online teaching during the pandemic. This is consistent with other reports (e.g., Elmer et al. 2020). The main contribution of this study is the documentation of changes in networks in 
more detail, and the visualisation of how networks are fragmented as they defoliate, or shrink from the outside in. As could be expected, weak ties are lost before strong ties. The most stable and resilient ties are those that are multiplex, that is consisting of individuals that are both friends and study partners. In this study, students report that the working network is the most important network for both well-being and outcome of studies, which is consistent with other studies (Fjelkner-Pihl, 202I), but in contrasts to yet other studies claiming that centrality in friendship networks is the most important factor in relation to study outcome (e.g., Rienties \& Tempelaar, 20I8).

Student from both universities reported on missing the informal interaction that went on in and around the classroom, although their experiences of social interaction differed depending on if they commuted or not. According to research on feedback (Esterhazy, 20I9; Henderson et al., 2019), interaction with many students near the study situation is important for students to understand content, instructions, and the overall meaning of courses. The question remains, interaction with how many? In this study, commuter students had smaller networks both before and during the pandemic than did non-commuters without generally reporting a decline in results or well-being. This observation opens for a possibility that even though learning and well-being is linked to interactions with others, different groups may have different needs.

Research on effects from the pandemic in a campus environment has shown that students during the pandemic struggled to orient themselves in courses and to find motivation to study (Warfvinge et al., 202I). Such signals surface also in our material. Pre-pandemic research into online teaching (Theobald et al., 20I8; Weidlich \& Bastiaens, 2019) emphasize study strategies and study discipline over opportunities to engage in a multitude of interactions. Overall, this leads to a conclusion that some students need the group and the myriad of interactions (Esterhazy, 2019) more than others, while some students rely on an already developed study discipline and their already existing working network.

Arguably and possibly not surprisingly, it is those students who struggle with their studies that are hit the hardest by the pandemic, especially those that have not been able to form functioning study groups before the pandemic. Since this sample consisted of students already into their third year, it is possible to foresee that more students would struggle if they had to start their studies under pandemic-like online conditions without sufficient support for social interaction, discussion groups, and group work in the online environment. In such a situation students must rely even more heavily on already constructed study strategies and those who lack such strategies would suffer difficulties.

Student networks became more fragmented after the emergency transition to online teaching. Figure I illustrates what this looks like on the cohort-level. Fragmentation increased dramatically. Since we know that study networks are formed by individuals who are similar to each other (Fjelkner-Pihl, 202I), thus following the principle of social homophily (McPherson et al., 200I), the pandemic may have led to a relative increase of social homophily. This type of fragmentation, besides from making it even harder for individuals to find others to work with, makes it more unlikely that students will interact with fellow students who think differently from themselves, something that several respondents pointed out in the open-ended answers. Even though short-term negative effects from increased partitioning in student cohorts have been validated (Rientes \& Templaar, 2018), research on long-term effects from increased social homophily is lacking. However, it has been established that students benefit from interacting with other perspectives, not only provided by the teacher (O’Donovan, 20I5; Perry, 1988). 
Finally, responses from our sample indicate that different students react differently to the online teaching during the pandemic. Commuters, for example, report doing well with a smaller working network as they maintain much of their social relations from before studying (e.g., Pokhorny et al., 2017; Thomas, 2019). LTH students, on the other hand, most of whom have chosen to study at a campus-institution, report both a decline in well-being and a loss of opportunities to interact with to them new students during the pandemic. Thus, post-pandemic planning for how to organize higher education should consider these and similar findings implying that one size does not fit all. The LTH students in our study both seek social presence from others and report being dependent on it, while students in the other end of the spectrum, the commuters, report doing well with less interaction and appeared more content with the changes made during the pandemic.

Furthermore, we argue that the fragmentation of cohorts and thereby a potential relative stronger dominance of social homophily is something that deserves attention, especially longitudinally. There is a risk that good study strategies and functioning working networks may maintain study efficiency short term despite increased cohort fragmentation, but also that they may hide a long-term negative effect on students' epistemological development. Considering the ethos of academia where personal and epistemological development are important, highlighting this risk might be the most important contribution from this study.

\section{LIMITATIONS}

The pandemic provided an opportunity to investigate effects on students' networks and to reflect on the meaning of these changes. An obvious limitation with this study is its ad hoc explorative nature. More stable conditions would possibly have allowed a more robust design. Second, the study is based solely on self-reported data which may reduce the validity of the study. Students may have over- or underestimated their relations, for various reasons, which may lead to a distortion of the data. At the same time, the study offers a snapshot view of student networks in two different settings during the Covid-I9 pandemic, and how these were differently affected due to the context. This is an important insight as we now move on and discuss how to organize higher education in the future.

\section{ABOUT THE AUTHORS}

Annika Fjelkner is a teacher and pedagogical developer at Kristianstad University, and currently also a doctoral student in pedagogical development at LTH, Lund. Her teaching mainly focuses the development of academic skills and academic writing, and research interest focuses student social networks and academic outcome.

Torgny Roxå is Associate Professor at the Centre for Engineering Education at the Faculty of Engineering, Lund University. His research focuses on strategic change in teaching cultures in higher education organizations, especially significant networks and microcultures, and he developed the first pedagogical academy, the Lund Excellent Teaching Practitioner.

Per Warfvinge is a Professor of Chemical Engineering and Director of the Centre for Engineering Education at the Faculty of Engineering, Lund University. He served as Assistant Dean at the faculty from 2001 to 2018 , holding responsibilities for teaching and learning as well as for international relations. 


\section{Annika Fjelkner et al.}

\section{REFERENCES}

Borgatti, S. P., Everett, M. G., \& Freeman, L. C. (2002). Ucinet 6 for Windows: Software for social network analysis. Analytic Technologies.

Eggens, L., Van der Werf, M. P. C., \& Bosker, R. J. (2008). The influence of personal networks and social support on study attainment of students in university education. Higher education, 55(5), 553-573. https://doi.org/10.1007/s10734-007-9074-4

Elmer, T., Mephan, K., \& Stadtfeld, C. (2020). Students under lockdown: Comparisons of students' social networks and mental health before and during the COVID-19 crisis in Switzerland. PLoS ONE, 15(7), 1-22. https://doi.org/10.1371/journal.pone.0236337

Esterhazy, R. (2019). Re-conceptualizing feedback through a sociocultural lens. In M. Henderson, R. Ajjawi., D. Boud, \& E. Molloy (Eds.), The impact of feedback in higher education (pp. 67-82). Springer. https://doi.org/10.1007/978-3-030-25112-3_5

Felten, P., \& Lambert, L. M. (2021). Relationship-Rich education: How human connections drive success in college. John Hopkins University Press.

Fjelkner-Pihl, A. (2021). The constructive overlap: A study of multiplex ties in students' study-related networks and academic performance. Innovative Higher Education, 1-23. https://doi.org/10.1007/ s10755-021-09576-4

Gothenburg University. (2020, September 30). Lärares upplevelse av distansundervisning med anledning av Covid-19. Samhällsvetenskapliga fakulteten. https://www.gu.se/nyheter/larare-och-studenteri-stort-nojda-med-distansundervisning

Grunspan, D. Z., Wiggins, B. L., \& Goodreau, S. M. (2014). Understanding classrooms through social network analysis: A primer for social network analysis in education research. CBE-Life Science Education, 13(2), 167-178. https://doi.org/10.1187/cbe.13-08-0162

Hanneman, R. A., \& Riddle, M. (2005). Introduction to social network methods. University of California.

Hattie, J. (2008). Visible learning - a synthesis of over 800 meta-analyses relating to achievement. Routledge.

Henderson, M., Ajjawi, R., Boud, D., \& Molloy, E. (2019). Identifying feedback that has impact. In M. Henderson, R. Ajawwi, D. Boud, \& E. Molloy (Eds.), The impact of feedback in higher education (pp. 15-34). Springer. https://doi.org/10.1007/978-3-030-25112-3_2

Hommes, J., Onyebuchi, A. A., de Grave, W., Schuvirth, L. W., Scherpbier, A. J., \& Bos, G. M. (2014). Medical students perceive better group learning processes when large classes are made to seem small. PLOS ONe, 9(4), e93328. https://doi.org/10.1187/cbe.13-08-0162

Husky, M., Kovess-Masfety, V., \& Swendsen, J. (2020). Stress and anxiety among university students in France during Covid-19 mandatory confinement. Comprehensive Psychiatry, 102(15191). https:// doi.org/10.1016/j.comppsych.2020.152191

Jeffrey, K., \& Bauer, C. (2020). Students' responses to emergency remote online teaching reveal critical Factors for All Teaching. Journal of Chemical Education, 97, 2472-2485. https://doi.org/10.1021/ acs.jchemed.0c00736

Krause, K.-L., Hartley, R., James, R., \& McInnis, C. (2005). The first year experience in Australian universities: Findings from a decade of national studies. Centre for the Study of Higher Education University of Melbourne.

Lund University. (2021). Forskningsetik och djurförsöksetik. https://www.medarbetarwebben.lu.se/forskaoch-utbilda/stod-till-forskning/forskningsetik-och-djurforsoksetik

London Higher. (2019). Commuter students in London: Results of a pilot project on factors affecting continuation. London Higher.

McCabe, J. M. (2016). Connecting in college: How friendship networks matter for academic and social success. Chicago University Press.

McPherson, M., Smith-Lovin, L., \& Cook, J. (2001). Birds of a feather: Homophily in social networks. Annual Review of Sociology, 27, 415-444. https://doi.org/10.1146/annurev.soc.27.1.415 
Methot, J. R., Lepine, J. A., Podsakoff, N. P., \& Siegel Christian, J. (2016). Are workplace friendships a mixed blessing? Exploring tradeoffs of multiplex relationships and their association with job performance. Personnel Psychology, 69, 311-355. https://doi.org/10.1111/peps.12109

O’Donovan, B. (2017). How student beliefs about knowledge and knowing influence their satisfaction with assessment and feedback. Higher Education, 74, 617-633. https://doi.org/10.1007/s10734016-0068-y

Oh, C., Bailenson, J., \& Welch, G. (2018). A systematic review of social presence: Definition, antecedents, and implications. Frontiers in Robotics and AI, 5, 1-35. https://doi.org/10.3389/frobt. 2018.00114

Perry, W. G. (1988). Different worlds in the same classroom. In P. Ramsden (Ed.), Improving learning: New perspectives (pp. 145-161). Kogan Page.

Pokorny, H., Holley, D., \& Kane, S. (2017). Commuting, transitions and belonging: The experiences of students living at home in their first year at university. Higher Education, 74, 543-558. https://doi. org/10.1007/s10734-016-0063-3

Rienties, B., \& Tempelaar, D. (2018). Turning groups inside out: A social network perspective. Journal of the Learning Sciences, 27(4), 550-579. https://doi.org/10.1080/10508406.2017.1398652

Savage, M., James, R., Magistro, D., Donaldson, J., Healy, L., Nevill, M., \& Hennis, P. (2020). Mental health and movement behaviour during the COVID-19 pandemic in UK university students: Prospective cohort study. Mental Health and Physical Activity, 19. https://doi.org/10.1016/ j.mhpa.2020.100357

Tomás-Miquel, J.-V., Expósito-Langa, M., \& Nicolau-Juliá, D. (2016). The influence of relationship networks on academic performance in higher education: A comparative study between students of a creative and a non-creative discipline. The International Journal of Higher Education Research, 71(3), 307-322. https://doi.org/10.1007/s10734-015-9904-8

Theobald, M., Bellhäuser, H., \& Imhof, M. (2018). Identifying individual differences using log-file analysis: Distributed learning as mediator between conscientiousness and exam grades. Learning and Individual Differences, 65, 112-122. https://doi.org/10.1016/j.lindif.2018.05.019

Thomas, L. (2019). Qualitative perceptions of students about commuting and studying in London. London Higher.

Wang, X., Hegde, S., Son, C., Keller, B., Smith, A., \& Sasangohar, F. (2020/21). Investigating mental health of US college students during the COVID-19 pandemic: Cross-sectional survey study. Journal of Medical Internet Research, 22(9), e22817. https://doi.org/10.2196/22817

Warfvinge, P., Löfgreen, J., Andersson, K., Roxå, T., \& Åkerman, C. (2021). The rapid transition from campus to online teaching-how are students' perception of learning experiences affected? European Journal of Engineering Education, 1-19. https://doi.org/10.1080/03043797.2021.1942794

Weidlich, J., \& Bastiaens, T. (2019). Designing sociable online learning environments and enhancing social presence: An affordance enrichment approach. Computers and Education, 142. https://doi. org/10.1016/j.compedu.2019.103622

William, D. (2011). What is assessment for learning? Studies in Educational Evaluation, 37(1) 3-14. https://doi.org/10.1016/j.stueduc.2011.03.001

Yorke, M., \& Longden, B. (2008). The first year experience of higher education in the UK: Final report. Higher Education Authority. https://www.heacademy.ac.uk/system/files/FYEFinalReport_1.pdf 